\title{
Cardiac Drugs Requirement during Off-Pump Coronary Artery Bypass (OPCAB) Surgery- A Comparison between Combined High Thoracic Epidural Anaesthesia (HTEA) with GA and GA Alone
}

\author{
SI Azad, AK Beg, AYFE Chowdhury \\ Department of Anaesthesiology, National Institute of Cardiovascular \\ Diseases (NICVD), Dhaka, Bangladesh.
}

Key word : Cardiac drug, HTEA, General Anaesthesia, $O P C A B$.

\begin{abstract}
:
Background : During off pump coronary artery bypass surgery (OPCAB) to provide adequate myocardial protection cardiac anaesthesiologist frequently needs to use various pharmacological intervention rather than physiological manipulation. This is challenging to overcome the adverse effects of the various drugs. During the past few years, high thoracic epidural anaesthesia (HTEA) as an adjunct to general anaesthesia has become more popular and has been shown to be potentially beneficial in patients with coronary diseases. It provides good protection from stress response, ensures hemodynamic stability, improves distribution of coronary blood flow and reduce demand for oxygen and perioperative arrhythmia.
\end{abstract}

Objective : This study has been undertaken with a view to compare the requirement of intraoperative cardiac drugs between HTEA with General Anaesthesia(GA) and GA alone.

Methods: Prospective, randomized case control study was undertaken in sixty patients, without having left main coronary disease, left ventreicular ejection fraction $<35 \%$ or contraindication of regional anaesthesia scheduled for OPCAB. They were divided into two groups, thirty in each group. Group A patients received GA alone and group B patients received high thoracic epidural anaesthesia with GA. Requirement of drugs (antiarrhythmic, inotropes, vasoconstrictor, vasodilators, Esmolol e.g.) during operation were recorded.

Results: Dopamine was needed in 27(90.0\%)patients in group A and 11(36.7\%) patients in group B, adrenaline was used in 15(50.0\%)patients in group $A$ and 4(13.3\%) in group B; Dobutamine was used only in 5(15.0\%) patients in group $A$ and ephedrine was required only in 2(5.0\%) in group $B$. Regarding the Antiarrhythmic drugs, Lignocanie, Amiodarone and DC Shock was required only in 17(55.0\%), 12(40.0\%) and 5(15.0\%) patients respectively only in group A. In vasodilators group, Nitropruside was used in 5(15.0\%) and 1(3.3\%) patients in group $A$ and group $B$ respectively. Esmolol was used in 17(55.0\%) patients in group A and 1(3.3\%) in group B. Significant $(p<0.05)$ difference were found in use of all drugs between two groups except Ephedrine and Nitropruside. Conclusion: The anaesthetic technique HTEA with GA required minimum intra operative cardiac drugs than GA only.

(Cardiovasc. j. 2010; 3(1) : 7-10)

\section{Introduction :}

Selective anaesthesia of $\mathrm{T} 1$ to $\mathrm{T} 5$ thoracic dermatomes with epidural local anaesthetic inhibits symphathetic innervation of the heart and regional vasculature, decreases left ventricular contractility and heart rate while prolonging phase
IV of the cardiac action potential. ${ }^{1}$ It decreases myocardial oxygen consumption, reduces arrhythmogenicity and increases diameter of the stenotic coronary arteries. ${ }^{2,3,4}$ Thus HTEA reduces hemodynamic correlates of the myocardial oxygen consumption, impaired regional (ischaemic zone)

Address of Correspondence : Dr. Md. Saiful Islam Azad, Dept. of Anaesthesiology, National Institute of Cardiovascular Diseases, Dhaka, Bangladesh.e-mail : saifulazad @yahoo.com 
endocardial perfusion and reduce the extent of the myocardial infarction in patients undergoing off pump CABG. ${ }^{5}$

Within the last few years, high thoracic epidural anaesthesia (HTEA) as an adjunct to general anaesthesia (GA) has become more popular ${ }^{6,7}$ and has been shown to be potentially beneficial in patients with coronary diseases. ${ }^{7}$ Thoracic epidural anaesthesia provides good protection from stress response, ${ }^{8,9,10}$ ensures hemodynamic stability, ${ }^{11}$ allows early extubation, ${ }^{12}$ improves distribution of coronary blood flow and reduces demand for oxygen. ${ }^{11}$ Patients have better postoperative pulmonary function and less postoperative pain. ${ }^{13,14}$ It also reduces the postoperative respiratory complications, perioperative arrhythmia such as supraventricular tachycardia $15,16,17$

\section{Aims and Objectives :}

To compare the requirement of intra-operative cardiac drugs such as antiarrhythmics, inotropes between HTEA with GA and GA alone.

\section{Materials and Methods :}

This Prospective, randomized case control study was undertaken at the National Institute of Cardiovascular Diseases, Dhaka. Sixty patients aged between 40 to 70 years of both male and female with physical status - American society of anaesthesiologist (ASA) - I ,II,III, \& IV ; New York Heart Association (NYHA) - I, II, III \& IV, scheduled for OPCAB were included in this study. They were divided into two groups, thirty in each group and were randomly selected by card sampling methods. Group A patients received GA alone and group $\mathrm{B}$ patients received high thoracic epidural anaesthesia with GA. Patient having left main coronary disease, left ventricular ejection fraction $<35 \%$, contraindication of regional anaesthesia were excluded. Informed written consent was taken from all patients on the preoperative day. Premedication with oral Midazolam 7.5mg was given in the night before surgery. Patients were fasted 6 hours before operation. After transferring the patients into the operation room, standard monitoring (five lead ECG, pulse Oxymetry) was done. All patients were pre-oxygenated with $100 \%$ oxygen. With all aseptic precaution intravenous cannulation, radial arterial catheterization and central venous catheterization was established. Epidural catheter was inserted at the level of T1-2 or T2-3 interspaces in the patients of group B. Fifteen minutes before surgery, high thoracic epidural anaesthesia was given in group $B$ patients with $0.25 \%$ Bupivacaine $10 \mathrm{ml}$ bolus followed by 8 $\mathrm{ml} / \mathrm{hr}$ through continuous epidural infusion during operative period and general anaesthesia was induced in all patients of both group with Fentanyl $10 \mu \mathrm{g} / \mathrm{kg}$ IV , Propofol $1 \mathrm{mg} / \mathrm{kg}$ IV .Tracheal intubations were facilitated by Pancuronium bromide $0.1 \mathrm{mg} / \mathrm{kg}$ and anaesthesia was maintained with Propofol infusion @ 50-100 $\mu \mathrm{g} / \mathrm{kg} /$ min, Fentanyl infusion@1-2 $\mu \mathrm{g} / \mathrm{kg} / \mathrm{hr}$, inhalation gas oxygen and air was given. Requirement of drugs (antiarrhythmic, inotropes, vasoconstrictor, vasodilators, Esmolol ) were recorded and the parameters including heart rate, SPO2, CVP, arterial blood pressure, arrhythmia in ECG, before induction, during induction, intubation and during different events of the surgery were monitored. At the end of the surgery, all patients were transferred to the intensive care unit.

\section{Results:}

The mean $( \pm \mathrm{SD})$ age was $49.9 \pm 7.1$ years in group $A$ and $49.3 \pm 7.2$ years in group $B$ with range from 40 to 70 years in both groups. No significant $(p>0.05)$ differences was found between two groups in relation to mean age.

The following table showed the drug requirement during operative period. 27(90.0\%) patients in group A and 11(36.7\%) patients in group B received Dopamine, 15(50.0\%) patients in group A and $4(13.3 \%)$ patients in group B received adrenaline, 5(15.0\%) patients in group $\mathrm{A}$ and nobody in group B received dobutamine and $2(5.0 \%)$ patients in group B received Ephedrine. Regarding the antiarrhythmic drugs $17(55.0 \%)$, $12(40.0 \%)$ and $5(15.0 \%)$ patients in group A received Lignocanie, Amiodarone and DC Shock respectively, however nobody in group $\mathrm{B}$ needed antiarrhythmic medication. In vasodilator group, $5(15.0 \%)$ and $1(3.3 \%)$ patients in group $\mathrm{A}$ and group B received Nitropruside respectively. Esmolol was used in 17(55.0\%) patients in group A and $1(3.3 \%)$ patients in group B. Significant $(p<0.05)$ difference was found in use of all drugs between two groups except ephedrine and nitropruside (Table I). 


\section{Table-I}

Distribution of drug requirement during operative period of the study patients $(n=60)$

\begin{tabular}{|c|c|c|c|c|c|}
\hline \multirow[t]{2}{*}{ Drugs } & \multicolumn{2}{|c|}{$\begin{array}{c}\text { Group A } \\
(\mathrm{n}=30)\end{array}$} & \multicolumn{2}{|c|}{$\begin{array}{c}\text { Group B } \\
(\mathrm{n}=30)\end{array}$} & \multirow[t]{2}{*}{$\mathrm{p}$-value } \\
\hline & $\mathrm{n}$ & $\%$ & $\bar{n}$ & $\%$ & \\
\hline \multicolumn{6}{|l|}{ Inotropes } \\
\hline Dopamine & 27 & 90.0 & 11 & 36.7 & 0.001 \\
\hline Adrenaline & 15 & 50.0 & 4 & 13.3 & 0.005 \\
\hline Dobutamine & 5 & 15.0 & 0 & 0.0 & 0.026 \\
\hline Ephedrine & 0 & 0.0 & 2 & 5.0 & $0.245 \mathrm{NS}$ \\
\hline \multicolumn{6}{|l|}{ Antiarrhythmic } \\
\hline Lignocanie & 17 & 55.0 & 0 & 0.0 & 0.001 \\
\hline Amiodarone & 12 & 40.0 & 0 & 0.0 & 0.001 \\
\hline DC Shock & 5 & 15.0 & 0 & 0.0 & 0.026 \\
\hline \multicolumn{6}{|l|}{ Vasodilators } \\
\hline GTN & 30 & 100 & 30 & 100 & - \\
\hline Nitropruside & 5 & 15.0 & 1 & 3.3 & $0.097 \mathrm{NS}$ \\
\hline Esmolol & 17 & 55.0 & 1 & 3.3 & 0.001 \\
\hline Digoxin & 0 & 0.0 & 0 & 0.0 & - \\
\hline
\end{tabular}

\section{Discussion:}

In the present study Dopamine (dose $1-20 \mu \mathrm{g} / \mathrm{kg} /$ min iv) was the first choice to maintain intraoperatively Mean Arterial Pressure (MAP) above $70 \mathrm{mmHg}$. If hypotension was not corrected with the Dopamine then direct acting agonist adrenaline (Epinephrine) $0.05-0.2 \mu \mathrm{g} / \mathrm{kg} / \mathrm{min}$ iv was added if the above drugs could not control the hypotension, Dobutamine $(2-20 \mu \mathrm{g} / \mathrm{kg} / \mathrm{min}$ iv) was used. Hypotension due to local anesthetic which was occurred immediate after given bolus dose through epidural catheter was managed with the vasoconstrictior Ephedrine $5-10 \mathrm{mg}$ iv bolus or repeatedly. Beta-adrenergic blocker Esmolol (0.25$0.5 \mathrm{mg} / \mathrm{kg}$ iv bolus) was used to control tachycardia, if not controlled amiodarone $5 \mathrm{mg} / \mathrm{kg}$ over $5-15$ minutes iv was also used. Injection lignocaine $1 \%$, $1 \mathrm{mg} / \mathrm{kg}$ iv route bolus then $1-4 \mathrm{mg} / \mathrm{kg}$ continuous infusion was given to control arrhythmia during operative period. Defibrillation (DC shock) was used for the treatment of ventricular arrhythmia (ventricular fibrillation, ventricular tachycardia).

Sodium nitropruside (dose 0.1-8.0 $\mathrm{g} / \mathrm{kg} / \mathrm{min}$ IV) $50 \mathrm{mg}$ mixed with $500 \mathrm{ml}$ normal saline $(100 \mu \mathrm{g} / \mathrm{ml})$ was given to reduce uncontrolled blood pressure.

Kundu et al. ${ }^{18}$ observed in their study Dopamine, Adrenaline, Dobutamine, Esmolol, Lignocaine were used in $80.0 \%, 20.0 \%, 80.0 \%, 20.0 \%$ and $60.0 \%$ patients in group A respectively. But Dopamine and Dobutamine was required in $20.0 \%$ and $20.0 \%$ patients in group B respectively.

Salvi et al. ${ }^{19}$ carried out a study in the Department of Anaesthesia and Intensive Care, Centro Cardiologico Monzino, Milan, Italy. Betaadrenergic blockers are extensively used in the above institution to induce bradycardia during the performance of anastomosis on the beating heart. In their study, none of the patients received betaadrenergic blockers intraoperatively, most likely because of the cardiac sympathetic blockade by HTEA. However, approximately $44.0 \%$ of the patients required vasopressors intraoperatively to maintain MAP above $70 \mathrm{mmHg}$. HTEA itself does not induce bradycardia, peripheral vasodilation, or hypotension if the blockade is restricted to the upper thoracic sympathetic segments (T1-T6). This technique was associated with stable intraoperative as well as postoperative central hemodynamics although nearly half of the patients required vasoconstrictor or vasodilator drugs. Kessler et al. ${ }^{6}$ observed Esmolol requirement was 25.0\% in group $\mathrm{A}$ and not required in group $\mathrm{B}$. The results obtained in the present study are comparable with the above studies.

In this study it is observed that during coronary artery anastomosis in the difficult territories of the heart, anesthetist and surgeon felt more comfort during positioning of the heart and during anastomosis of the graft due to better cardiovascular stabilities in group B.

\section{Conclusion:}

Based on the present study results, the anaesthetic technique HTEA with GA required minimum intra operative cardiac drugs than GA only and during OPCAB.

\section{References:}

1. Goertz AW, Seeling W, Heinrich H. Influence of high thorasic epidural anesthesia on left ventricular contractility assessed using the end systolic pressure length relationship. Acta Anaesthesiol Scand 1993;37:38133.

2. Blomberg S, Curelaru I, Emanuelsson H. Thoracic epidural anaesthesia in patients with unstable angina pectoris. Eur Heart J 1989;10:437-44.

3. Reiz S, Nath S, Ponten E. Hemodynamic effects of prenalterol, a beta adrenoreceptor agonist, in hypotension induced by high thoracic epidural block in man. Acta Anaesthesiol Stand 1979;23:93-6. 
4. Kock M, Blomberg S, Emanuelsson H. Thoracic epidural anesthesia improves global and regional left ventricular function during stress induced myocardial ischemia in patients with coronary artery disease. Anesth Analg 1990;71:625-30.

5. Davis RF, deBoer LW, Maroko PR. Thoracic epidural anesthesia reduces myocardial infarct size after coronary artery occlusion in dogs. Anesth Analg 1986; 65: 711-7.

6. Kessler P, Aybek T, Neidhart G, dogan S, Lischke V, Bremerich DH. Comparison of three anesthetic techniques for Off-pump coronary artery bypass grafting: general anaesthesia, Combined general and high thoracic epidural anaesthesia, or high thoracic epidural anesthesia alone. $J$ of Cardiothoracic Vasc Anesth 2005;19(1): 32-39.

7. Dean GD and Kim SJ. A survey of spinal and epidural techniques in adult cardiac surgery. $J$ Cardiothoracic Vasc Anesth 2001;15:158-168.

8. Olivier JF and Le N. Comparison of the three different epidural solutions in off-pump cardiac surgery: pilot study. Br J Anaesth 2005;95(5):685-691.

9. Moore CM, Cross MH, desborough JP, Burrin JM, Macdonald IA, Hall GM. Hormonal effects of thoracic extradural analgesia for cardiac surgery. $\mathrm{Br} J$ Anaesth 1995;75:387-93.

10. Ganapathy S, Murkin JM, Dobkowski W, Boyd D. Stress and inflammatory response after beating heart surgery versus conventional bypass surgery: the role of thoracic epidural anesthesia. Heart Surg Forum 2001;4:323-7.

11. Stenseth R, Berg EM, Bjella L, Christensen O, Levang OW, Gisvold SE. Effects of thoracic epidural analgesia on coronary hemodynamics and myocardial metabolism in coronary artery bypass surgery. J Cardiothorac Vasc Anesth 1995; 9: 503-9.
12. Stenseth R, Bjella L, Berg EM, Christensen O, Levang OW, Gisvold SE. Thoracic epidural analgesia in aortocoronary bypass surgery. I: haemodynamic effects. Acta Anaesthesiol Scand 1994; 38: 826-33.

13. Joachimsson PO, Nystrom SO, Tyden H. Early extubation after coronary artery surgery in efficiently rewarmed patients: a postoperative comparison of opioid anesthesia versus inhalation anesthesia and thoracic epidural analgesia. J Cardiothorat Anesth 1989;3:444-54.

14. Leim TH, Hasenbos MA, Booij LH, Geilen MJ. Coronary artery bypass grafting using two different anesthetic techniques. Part 2: Postoperative outcome. J Cardiothorac Vasc Anesth 1992;6:156-61.

15. Hemmarling TM, Prieto I, Choiniere JL, Basile F, Fortier JD. Ultra-fast-track anesthesia in off-pump coronary artery bypass grafting: a prospective audit comparing opioid based anesthesia vs thoracic epidural -based anesthesia. Can J Anaesth 2004;51:163-8.

16. Scott MB, Turfrey DJ, Ray DA. Aprospective randomized study of the potential benefits of thoracic epidural anaesthesia and analgesia in patients undergoing coronary artery bypass grafting. Anesth Analg 2001;93(5):28-35.

17. Turfrey DJ, Ray DA,Suteliffe NP, Ramayya P, Kenny GN, Scott NB. Thoracic epidural anaesthesia for Coronary artery bypass graft surgery. Effects on postoperative complications. Anaesthesia 1997;52:1090-5.

18. Kundu RK, Beg AK, Hossain S, Haque N, Mahafuddoza, Chowdhury A. Comparative study of haemodynamic status and arrhythmia between combined epidural with general anaesthesia and general anaesthesia alone in Off-pump coronary artery bypass (OPCAB) surgery. $J$ Bangladesh Coll Phys Surg 2008;26:116-120.

19. Salvi L, Sisillo E, Brambillasca C, Juliano G, Salis S and Marino MR. High thoracic epidural anesthesia for offpump coronary artery by pass surgery. $J$ Cardiothorac Vasc Anesth 2004;18(3):256-62. 